\title{
Dossiê
}

\begin{tabular}{l} 
REsumo \\
Quais discursos vêm sendo \\
produzidos sobre a(as) infân- \\
cia(as) na contemporaneidade? \\
Realizar esse questionamento, \\
à luz da psicanálise, é o ob- \\
jetivo principal deste artigo \\
que também incita reflexões \\
a respeito dos processos de \\
judicialização, medicalização e \\
mercantilização dos primeiros \\
estágios da vida. Compreende- \\
se que os momentos iniciais do \\
desenvolvimento repercutem \\
no modo de funcionamento \\
do sujeito. De modo que as \\
maneiras com as quais os \\
grupos sociais lidam com suas \\
diferentes crianças exercerão \\
influências noprojeto de futuro \\
de cada sociedade. Assim, \\
confirma-se a relevância de \\
pensar sobre o tema "sofrimen- \\
to psiquico na infância e seus \\
desdobramentos". \\
Descritores: sofrimento \\
psíquico; infância; judicia- \\
lização; medicalização; \\
mercantilização. \\
\hline
\end{tabular}

\section{INFÂNCIA E SOFRIMENTO PSÍQUICO: MEDICALIZAÇÃO, MERCANTILIZAÇÃO E JUDICIALIZAÇÃO}

\author{
Carlos Mendes Rosa \\ Lana Veras \\ Junia Vilhena
}

DOl: http://dxdoi.ors/10.11606/issn. 1981-1624.v20i2p226-245.

Nas praias de mundos sem fim crianças encontram-se. O céu infinito é imóvel acima e a água agitada é tumultuosa. Nas praias de mundos sem

fim as crianças encontram-se com gritos e danças.

Elas constroem suas casas com areia e brincam com conchas vazias. Com folhas murchas tecem seus barcos e sorrindo fazem-nos flutuar no vasto profundo. Crianças brincam nas praias de mundos sem fim. (Rabindranath Tagore)

- a Professor de Psicologia da Universidade Federal do Tocantins (UFT). Pesquisador Associado do Laboratório Interdisciplinar de Pesquisa e Intervenção Social (LIPIS) da Pontifícia Universidade Católica do Rio de Janeiro (PUC-Rio), Palmas, TO, Brasil.

n a Psicóloga. Professora Adjunta da Universidade Federal do Piauí (UFPI), Teresina, PI, Brasil.

- a - Psicanalista. Professora do Programa de Pós-Graduação em Psicologia Clínica e coordenadora do Laboratório Interdisciplinar de Pesquisa e Intervenção Social (LIPIS) da Pontifícia Universidade Católica do Rio de Janeiro (PUC-Rio), Rio de Janeiro, RJ, Brasil. 


\title{
Introdução
}

\begin{abstract}
As despesas do velório e do traslado do corpo para a cidade natal de sua família no Piauí. Essa foi a última intervenção do Estado na história do menino de 10 anos, Eduardo de Jesus Ferreira. O garoto foi morto com um tiro de fuzil, em abril de 2015 , na porta da casa onde vivia com a família desde a desapropriação da sua última residência para a construção de um teleférico, no morro do Alemão, Rio de Janeiro.

A trágica morte de Eduardo alcançou visibilidade midiática. Ela ocorreu poucos dias após a aprovação, pela Comissão de Constituição e Justiça da Câmara dos deputados, da admissibilidade da Proposta de Emenda à Constituição 171/93, que propõe a redução da maioridade penal de 18 para 16 anos. Com a continuidade da tramitação da referida PEC, entrou em ebulição na mídia e nas redes sociais a temática "criança e adolescente" ou "menor infrator", as denominações variam consoante seus emissores. $\mathrm{Na}$ invisibilidade do cotidiano das periferias brasileiras, muitos "menores" são mortos como nos versos de João Bosco, em De frente pro crime: “Tá lá o corpo/Estendido no chão/Em vez de rosto uma foto/De um gol/Em vez de reza/Uma praga de alguém/E um silêncio/Servindo de amém...”.
\end{abstract}


Ao observar a repercussão do assassinato de Eduardo, foi frequente visualizarmos a tentativa de situá-lo em um desses "lugares". Ora figuravam narrativas que o representavam como uma criança com um caderno escolar na porta de casa, ora suposições que o ligavam ao tráfico (mesmo sem quaisquer indícios de tal fato). De maneira que, o pertencimento a um polo ou a outro fazia com que sua morte fosse lamentada por uns, ou justificada por outros.

Atualmente, no Brasil, percebemos a anuência da maioria da população e da mídia a uma possível aprovação da redução da maioridade penal, com a concepção de que crianças e adolescentes que não agissem "conforme as normas" teriam completa responsabilidade pelos seus atos e deveriam ser punidos pela justiça como adultos.

No entanto, seria essa lógica aplicada da mesma maneira às crianças, aos "menores", de todos os contextos socioeconômicos e culturais?

Esse questionamento incita reflexões a respeito dos discursos que vêm sendo produzidos sobre a(s) infância(s) na contemporaneidade e que se organizam ao redor de três eixos principais: a judicialização, a medicalização e a mercantilização.

Se, por um lado, temos um exorbitante número de mortes de "menores" negros e pobres por "autos de resistência" - quando a ação violenta é justificada pela não obediência a alguma ordem policial, por exemplo
- para as outras crianças e adolescentes, temos, por outro lado, um incremento de diagnósticos do que o Manual Diagnóstico e Estatístico de Transtornos Mentais denomina de "Transtorno Desafiador Opositivo" (TOD). Essa patologia se caracterizaria essencialmente por comportamentos de desobediência às figuras de autoridade e às normas (APA, 2002).

O Manual, uma publicação da Associação Norte-Americana de Psiquiatria, que recebe financiamento da indústria farmacêutica, estabelece que o jovem que apresente quatro das características listadas a seguir teria tal patologia:

1) perde a calma com frequência; 2) frequentemente tem discussões com adultos; 3) constantemente desacata ou se recusa a obedecer a solicitaçóes ou regras de adultos; 4) adota um comportamento bastante incomodativo; 5) costuma responsabilizar os outros por seus erros ou comportamento inadequado; 6) mostra irritação com facilidade; 7) geralmente está enraivecido e ressentido, e; 8) apresenta-se como rancoroso ou vingativo (APA, 2002).

Segundo pesquisa de autor patrocinado pelos laboratórios Pfizer, Janssen-Cilag, Eli Lilly, Wyeth, Novartis e GlaxoSmithKline, os jovens com esse diagnóstico de TOD deveriam ser tratados com medicamentos psicotrópicos e terapia cognitivo-comportamental. Na grande maioria dos casos, há evolução para o chamado "Transtorno da Conduta", caracterizado por sérias violações aos 
direitos alheios e normas sociais (Barletta, 2011; Serra-Pinheiro, Schmitz, Mattos, \& Souza, 2004).

Constatamos que os discursos sobre a infância e adolescência na atualidade não são homogêneos, mas transitam entre a judicialização para uns, a medicalização para outros e a mercantilização para todos. A depender das circunstâncias, nossa sociedade dirá: "crime, bandido, cadeia e morte" ou "doença, criança/adolescente, tratamento", contudo, todos serão atravessados pela mercantilização, seja como consumidor ou como produto.

Em nome da proteção dos jovens, ou de se proteger deles, novas formas de controle social são engendradas e as intervenções na infância aumentam. Em uma direção, a judicialização se transforma em uma política de vida e realiza a "clivagem" da infância, que passa a ser alvo de atenção/controle, recebendo os papéis de "vítima" e "delinquente" (Marafon, 2014). Em outra direção, a medicalização rotula como "patológicas" questões anteriormente definidas por outras áreas e, segundo Conrad (2007), de duvidosa natureza médica. O encontro desses caminhos é costurado pela mercantilização que transforma as "soluções" em produtos, sejam judiciais ou médicos, e os vende.

\section{A construção da infância}

Se, pela lente psicanalítica, a infância é o período mais importante de toda a vida do sujeito, como pensar as repercussões que o quadro apresentado na introdução deste artigo podem gerar?

Os teóricos mais renomados da psicanálise são unânimes em afirmar que as estruturas psíquicas, as patologias, e mesmo o modo de funcionamento do sujeito, são todos definidos nos primeiros estágios da vida. De modo que, as maneiras com as quais cada sociedade lida com suas diferentes crianças certamente exercerá influência em seu projeto de futuro.

Historicamente, apesar da sua importância radical, a infância teve um status marginal na sociedade. $\mathrm{O}$ estudo clássico de Ariès (1981) sobre a história da família e das crianças aponta que, até a Idade Média, não existia a noção de criança que temos hoje. Esta era tratada como um coadjuvante no seio familiar, ou mesmo como um adulto pequeno e atrapalhado. 
É a Pedagogia dos séculos XVIII e XIX que inventará uma crianel ça para fazer figuração ao casal burguês. Ela se torna a finalidade da união entre homem e mulher no novo modelo de família conjugal que confisca e absorve a sexualidade na seriedade da função reprodutora (Foucault, 1998). É também uma criança que, sabe-se, não tem sexo, boa razão para lhe fechar os olhos e tapar os ouvidos. A chamada educação sexual, escamoteada pelo viés pedagógico, enreda as crianças em uma teia de discursos sobre o sexo em que, ora se dirigem a elas, ora falam delas, ou mesmo as fazem falar, dispondo uma série de dispositivos institucionais de controle. Só mais tarde, com a atitude despudorada de Freud ao lançar seus "Três ensaios para uma teoria da sexualidade", é que o tabu da sexualidade infantil será desvelado para escândalo e reprovação da maior parte da sociedade (Freud, 1905/1996a).

Ainda assim, a criança continuará tendo um lugar quase de "objeto do adulto" nas dinâmicas psicossociais. Essa se torna vítima de processos sociais e psicológicos bastante complicados, como os já adiantados no início deste texto: a judicialização, a medicalização e a mercantilização da infância. Reflexos bastante nítidos de nossa organização social, pois como afirmou Nelson Mandela: "Não existe revelação mais nítida da alma de uma sociedade do que a forma como esta trata as suas crianças".

Esses temas serão abordados de forma reflexiva neste texto, tendo como balizadores os olhares da psicologia social e da psicanálise. Para tanto, vamos partir do pressuposto que exista uma criança da qual possamos falar. É claro que essa suposição é meramente didática e não corresponde à realidade de infâncias absolutamente desiguais que podem ser encontradas no contexto atual de nossa sociedade.

\section{A criança dentro dos muros}

O primeiro aspecto que queremos enfocar é a judicialização de crianças consideradas diferentes do ideal de pureza, bondade e saúde que os estereótipos sociais insistem em imputar aos seus pequenos sujeitos. A jornalista literária Eliane Brum escreveu um texto perturbador em sua coluna do Jornal El Pais (2014), cujo título é "Como se fabricam crianças loucas". No diálogo abaixo, livremente inspirado nessa matéria jornalística, a "menina louca", como é chamada por 
Eliane, indaga sobre a estrutura do Estado e da sociedade que a obriga a dar o primeiro passo para dentro de uma instituição psiquiátrica.

A menina dentro da ambulância pergunta à psicóloga:

- Por que eu vou ficar aqui?

A psicóloga descobriu que não tinha resposta.

A menina fez então a segunda pergunta:

- Quem tá aí? Quem vai dormir no quarto comigo?

A pergunta feita à psicóloga e a todos nós foi a seguinte: por que, no século XXI, crianças brasileiras, em sua maioria filhas de famílias pobres, continuam a ter suas vidas mastigadas num hospital psiquiátrico? A "criança louca" faz aos "normais" a pergunta mais lúcida: por que a condenavam a uma existência no manicômio? A habitar um mundo de dor, vagando entre paredes, desvestindo de si mesma para vestir um uniforme, sem direito ao desejo. Por que lhe negam a humanidade tão cedo? (Brum, 2014).

Isso porque a nossa memória recente ainda guarda os resquícios dos horrores que ocorriam antes do início da luta antimanicomial (que ainda não acabou). Daniela Arbex (2013) conta em seu livro Holocausto brasileiro que mais de trinta crianças foram jogadas, algumas ainda bebês, no maior hospício do Brasil: o Hospital Juliano Moreira de Barbacena; e lá permaneceram por mais de cinquenta anos (a maioria nunca saiu). 
Mas o que significa uma criança institucionalizada? Muitas vezes só lhe resta aguardar a palavra dos especialistas. Durante esta longa espera, ela tende a se institucionalizar, não somente pelos efeitos provocados pelo prolongado tempo de enclausuramento, mas também como uma maneira de sobreviver dentro da instituição. A criança se vê tanto acomodada às normas estabelecidas, quanto contaminada e invadida por elas. Observa-se, mesmo em pacientes adultos, que estes tendem a se tornar passivos diante da vida e cronificados em sua doença. O que dizer de uma criança?

O mesmo pode ser dito sobre crianças condenadas a penas nas instituições denominadas "socioeducativas". Sobre estes menores falaremos mais adiante. Mas pensemos no que significado de criança "institucionalizada".

Sabemos da importância de entender a instituição - no sentido proposto por Goffman (1961) - considerando os seus agenciamentos, suas relações de forças e os dispositivos de poder que a constituíram. É comum, quando se pensa em poder, associá-lo à ideia de violência, repressão, domínio, sujeição de um indivíduo (ou de um sistema) sobre o outro.

As instituições totais se apresentam como ambientes de fechamento sociorrelacional dos sujeitos, tornando a variedade de interações nos diversos planos da vida, em uma única, monótona e massacrante forma de se relacionar. A rotina imposta, as vestimentas, as regras, tudo colabora para a mortificação do eu por meio da supressão brutal dos valores individuais e culturais. Todas as liberdades estão revogadas em um período da vida no qual ser livre é fundamental para a formação da personalidade. A noção de privilégio como ausência de privação nos parece tão desconectada das realidades social e psíquica, que pensamos na violência simbólica de tal contexto à subjetividade (Goffman, 1961).

Foucault (2000) lembra em sua magnífica obra sobre as prisões, Vigiar e punir, que a forma geral de uma aparelhagem tornar os indivíduos dóceis e úteis através de um trabalho preciso sobre seu corpo, foi a criação da instituição-prisão antes mesmo da lei a definir como a pena por excelência.

Para Foucault (2000), as prisões são exemplos de instituições pensadas e concebidas com o objetivo de excluir parte da sociedade. Assim como o hospital, a prisão nasce no século XVII como um lugar que em vez de aproveitar seu espaço para promover a cura, a readaptação e a recuperação, torna-se um depósito destinado a todos os que eram considerados inadequados. Não raro, tanto os hospitais psiquiátricos, quanto as prisões, nunca vislumbraram a atenção à saúde e a reinserção do indivíduo na sociedade. As características dessas instituições são uma separação decidida entre os que têm poder e os que não o têm.

Além desse quadro sombrio em que crianças ainda passam vários 
anos de sua infância em um manicômio ou instituição "sociocorretiva", a contemporaneidade também trata de colaborar com a criação de novas insígnias diagnósticas que patologizam comportamentos infantis antes considerados normais. Tal é o caso dos signos clínicos TDAH (Transtorno de Déficit de Atenção com Hiperatividade) e TOD (Transtorno Opositor Desafiador), os quais não possuem qualquer marcador biológico que ateste sua existência, e nos parecem muito mais convenções que servem aos interesses vigentes em algumas classes.

Mario Eduardo Costa Pereira escreveu um artigo muito interessante cujo título é "Diagnóstico e alienação ou 'Doutor, meu filho é TDAH"'. A afirmação que a mãe dirige ao médico, utilizada para compor o título do texto, é emblemática do atual quadro que se instala em relação à infância. A mãe não diz ao médico "o meu filho está com TDAH”, ou ainda “ele tem TDAH”. Ela afirma que ele é TDAH. Se pensarmos como Lacan (1998), que um significante representa o sujeito para outro significante, percebemos que, neste caso específico, um significante provindo do campo do Outro socialmente aceito e valorizado (no caso, a medicina) entra no lugar do significante que deveria representar a identidade do filho para a mãe, a escola.

$\mathrm{O}$ artigo narra o percurso de uma criança encaminhada ao psiquiatra pela própria escola que, enxergando naquele infante um problema, solicita à mãe uma providência. Isso porque a atual pedagogia tende a se ocupar de uma criança idealizada, que é silenciosa, atenta, disciplinada... Em suma, sem as marcas da sexualidade perversa polimorfa descritas por Freud (1905/1996a) em seus "Três ensaios para uma teoria da sexualidade".

A mãe então endereça o seu pedido de ajuda nos termos descritos. Nesse momento, o clínico precisa ser radical em sua posição de questionar a validade do rótulo imposto à criança (Pereira, 2007). Uma postura mediadora ou complacente é mais que suficiente para dar prosseguimento à cadeia representacional nociva que se instalou com o "diagnóstico" da escola e culminaria na prescrição de psicofármacos ao menino TDAH.

O furor diagnóstico em relação à infância é sintomático do nosso tempo. Se por um lado colocam as crianças muito novas em rotinas diárias comparadas às dos grandes executivos do mercado, algo que limita as possibilidades de expressão da criatividade e vazão da agressividade natural dos pequenos - lembrando que Winnicott (1975) valorizou, acima de tudo, o brincar da criança como condição para o desenvolvimento de um adulto saudável e com recursos para viver a vida em sua plenitude -, Por outro lado, busca-se na medicina a segurança de estar formatando o comportamento infantil nos moldes do que é esperado pelo social. 
O esperado é que a criança seja feliz, afinal de contas, a infância, de acordo com os estereótipos vigentes, é um paraíso. Segundo Contardo Caligaris (2004), essa é a mais complicada das exigências feitas à criança: que ela seja feliz, ou melhor, que tente encenar a felicidade para os adultos, como forma de recuperar aquilo que eles nunca tiveram. Uma revivescência do narcisismo perdido, tal como analisou Freud (1914/1996b) acerca da relação dos pais com seus filhos. Nesse sentido, o ideal de felicidade que os pais colocam nas crianças é algo da ordem do "você deve ser feliz porque eu não consigo ser".

Experimentar a alternância entre vivências de alegria e de tristeza faz parte da experiência pessoal da maioria dos seres humanos, porém, na contemporaneidade, a proporção esperada de cada um desses polos tem sido bastante modificada (Veras, 2015). Nesse contexto de exigência (obrigação) de ser feliz, a psiquiatria não se limita apenas ao tratamento, mas ao alívio do sofrimento inerente à vida cotidiana e aos limites naturais da vida, bem como pela produção biotecnológica de estados de felicidade (Bezerra Jr., 2010).

Ao menor sinal de infelicidade dos filhos, recorremos ao arsenal farmacêutico de ritalinas e antidepressivos como mecanismo de reestabelecimento do status "normal" da infância e também como complemento (ou substituto) da educação que deveria ser fornecida pelos pais e cuidadores. 
Entramos aqui no aspecto da medicalização na infância, tão problemática em diversos setores da vida cotidiana e em todas as faixas etárias, mas particularmente devastadora para as crianças que não têm voz ativa para protestar e sequer entendem aquilo que está acontecendo.

Nesse contexto, a criança aparece como sintoma da organização social e psíquica dos pais e das instituições que dela deveriam se ocupar. E o sintoma da criança, aquilo que a singulariza e a define como sujeito (tristeza, agressividade, hiperatividade), fica excluído do campo de análise, encoberto por rótulos e atenuado por medicamentos.

Nesse cenário, nos parece imperativo que se leve em conta os vários contextos sociais em que a infância é construída e se esforce por viabilizar a construção de um enigma sobre o sintoma da criança, seja ele qual for, permitindo que ela produza um saber novo sobre seu inconsciente e seu desejo.

\section{Infância para quê?}

Também é valido considerar que estamos num momento histórico de mudança na ordem familiar, de maneira que as figuras parentais não encontraram um equilíbrio entre seus projetos existenciais singulares e o cuidado familiar dos filhos. Com isso, a fragilidade do investimento afetivo se faz presente com os desdobramentos 
nefastos que isso provoca (Birman, 2006).

Além disso, Winnicott (1987) adverte que crianças que têm confiança nos pais provocam constantes sobressaltos. Buscam exercer o seu poder de destruição e optam por ameaçar, desperdiçar, seduzir e se apropriar de objetos. Todas as coisas que são passíveis de penas criminais na idade adulta têm seus correspondentes expressos na infância normal através da relação entre a criança e seu lar. Ocorre que, se o lar consegue suportar com êxito tudo que a criança faz para destruí-lo, ela acaba por se acalmar e passa a dirigir seus impulsos para o brincar.

No entanto, não são todas as famílias que têm condições sociais ou psicológicas de oferecer um ambiente adequado para seus filhos. Nesses casos, muitas vezes a criança expressa suas insatisfações, dúvidas e angústias no âmbito da sociedade. Nas classes média e alta, os efeitos costumam ser sentidos na escola.

Já as crianças e adolescentes das classes populares, muitas vezes privados do direito à educação, terminam por transgredir a norma vigente. Quando isso acontece, o Outro social se arma de leis e força policial para conter e punir (o termo usado é "socioeducar"), não mais a criança, mas o menor que agora se tornou infrator, desconsiderando que a origem do desajustamento da criança está no ambiente que não a acolheu quando ela precisou. Podemos pensar no fracasso da família em curar os efeitos dessas deficiências, mas trata-se também de um fracasso da sociedade, quando esta toma o lugar da família (Winnicott, 1963).

Propomos uma distinção entre menor e criança: criança é meu filho, o filho dos amigos, dos irmãos, as crianças queridas por nós, e que são parecidas conosco; "menor" é o ser temível que está nas ruas, cometendo crimes contra a ordem pública e sendo preso (Vilhena, Zamora, \& Rosa, 2012). Sabemos o que quer dizer a palavra menor, termo nitidamente pejorativo - ou será que algum de nós convida os menores do condomínio onde mora para o aniversário do filho? Menor é o Outro assustador dentro da criança e na criança, estragando a imagem de inocência e pureza ainda sustentada pela sociedade, entre outras razões, por uma finalidade mercantilista de cativar os corações consumistas.

\section{falso brilho do consumo}

Sobre a questão do consumo, que, segundo Lipovetsky (2007), torna-se um dos pilares da formação identitária na contemporaneidade, quando outras instituições como a religião, a tradição e a política perdem força, podemos comentar que a criança do nosso tempo nasce inserida no contexto do consumo. Seduzidas pelas mais variadas ofertas de brinquedos, roupas etc., tornam-se alvo de um 
mercado ávido por novos consumidores. Por essa razão, apresentam atitudes e comportamentos que denotam características de uma "nova infância" capturada pela sedução da imagem e convencidas quanto ao valor dos signos como modo de conquista de um lugar individual prestigiado (Bittencourt, 2012).

Segundo Lipovestky (2007), nossa cultura estaria alicerçada em três axiomas principais: o mercado, a eficiência técnica e o indivíduo. Tais axiomas se entrelaçam atuando diretamente sobre a subjetividade e na relação que os sujeitos contemporâneos estabelecem com seus pares. O desenvolvimento desenfreado da tecnologia, a lógica que permeia a chamada "cultura de consumo" e a busca frenética pela felicidade, transformada no grande dever moral da atualidade, parecem incidir diretamente no modo como nos relacionamos na contemporaneidade.

Estamos entrando no território recente da mercantilização da infância, com suas duas faces principais: a criança alvo dos produtos do mercado e a criança produto do mercado. Sobre o primeiro aspecto, podemos introduzir a fórmula lacaniana de desejar para sentir falta (ou o princípio básico do marketing). Buscar o objeto a (causa do desejo) como forma de escapar da angústia que acomete a todos, pois uma sociedade que se alimenta do livre fluxo de energia, como a de consumo, tem como efeito a diminuição da capacidade de representação do sujeito. Assim, a subjetividade angustiada dos dias atuais torna-se presa fácil do aliciamento das "propagandas espetáculo", ainda que estas causem mais sofrimento (depreciação) do que realização.

Se essa maneira de pensar é válida para os adultos que já possuem um aparelho psíquico formado (o qual deveria ser capaz de responder às demandas criadas pela publicidade), o que se dirá da criança cujo psiquismo, e especialmente o superego, ainda está em construção? Vemos uma torrente de sugestões que incitam e excitam o desejo de consumir todo e qualquer tipo de produto ser apresentada à criança que não têm o devido preparo para dizer "não" a tais ofertas, pois, como aprendemos com Freud, o desejo é a mola mestra das ações do sujeito que, em sua vontade de se satisfazer, desconhece quaisquer obstáculos morais ou pragmáticos. É necessário que exista uma instância reguladora para barrar o impulso ao prazer. Instância essa que ainda não existe em sua plenitude nos infantes.

Podemos dizer ainda, de acordo com Lacan (2005), que: 
o desejo é coisa mercantil que há uma cotização do desejo que se faz subir e baixar culturalmente, e que do preço que se dá ao desejo no mercado dependem a cada momento a forma e o nível do amor. $\mathrm{O}$ amor, na medida em que ele mesmo é um valor, como muito bem dizem os filósofos, está feito da idealização do desejo (p. 195).

Mirian Debieux Rosa (2005) discute essa nova configuração da sociedade, onde o discurso capitalista estabelece uma concepção de funcionamento social em que o indivíduo se adapta a uma realidade dada. Sobre esse aspecto, Lacan destaca o "valor de uso", que define como "o máximo de utilidade para a maioria". Destaca, no entanto, que há algo além no valor de uso, pois "há sua utilização de gozo.... Freud já nos abrira esse caminho: dispor de seus bens é ter o direito de privar os outros deles. Agora, se o sujeito pode dispor de seus bens, pode também defendê-los, isto é, pode proibir a si mesmo de gozar deles" (Lacan, 1988, p. 279)

Tal discurso privilegia não o sujeito, mas o indivíduo consumidor que, em sua dimensão de consumidor, não encontra lugar para seu pathos (sofrimento), para formular demandas, remetido que fica à colagem do objeto da demanda ao objeto do consumo. O sistema gera uma nova economia libidinal que exclui o pathos e substitui a demanda de amor pelo apelo ao consumo e ao lucro sobre o outro. 
Porque, como bem aponta Lacan (1988), "o valor de uma coisa é a sua desejabilidade - trata-se de saber se ela é digna de ser desejada, se é desejável que a desejemos" (p. 24).

Isso significa que, existe, no capitalismo, uma passagem do eu ideal - que regula o sujeito com marcas das insígnias do Outro, conduzindo-o a uma esperança de reconhecimento para uma outra instância que seduz e escraviza o sujeito com a sua voz, ordenando-o ao gozo ou assombrando-o com o fracasso, caso não se atenda à suposta realidade (Rosa, 2005). Ou, nas palavras de Lacan (1992), uma "mutação capital" que confere ao discurso do Mestre seu estilo capitalista (p. 160). Tal lógica se encontra em estreita relação com as cobranças feitas a todos nós, no sentido de sermos os únicos responsáveis pelo sucesso ou fracasso de nossas trajetórias. O termo "sucesso" aqui, quando bem entendido, trata-se do atingimento de uma série de metas previamente estabelecidas pela lógica consumista e individualista da sociedade espetacular.

Se a pedagogia do século XIX inventou uma criança e um conceito de infância para o projeto moderno civilizador, as instâncias midiáticas reinventam essa criança para o consumo de seus produtos. Essas não aparecem mais como inocentes e imaturas, mas como pequenas mulheres provocantes, desfilando, fazendo poses e demonstrando que sabem exatamente o que querem comprar (Carvalho \& Serpa, 2014).

Neste sentido, os concursos de beleza para meninas de 3 anos de idade, iniciados nos Estados Unidos e imitados em diversos países, inclusive no Brasil, não deixam de causar estranhamento por se constituírem em verdadeiras agressões à integridade das crianças, com a dupla finalidade de satisfazer as aspirações narcísicas dos pais e alimentar ainda mais o crescente e próspero mercado consumidor infantil. Aqui a criança se torna, além de consumidora de produtos espetáculo, um produto a ser consumido. Pois, como já afirmava Muniz Sodré (1994), o efeito vitrine é a vocação por excelência da ideologia contemporânea.

Essa também é a concepção de Michel de Certeau ao afirmar que o desenvolvimento tecnológico nos leva a viver muito mais no mundo da fantasia, no registro do imaginário (Certeau, 1994). Freud dirá que se o sintoma é neurótico, a fantasia é perversa. Ambos são secundários em relação à primeira experiência de satisfação e supõem a perda do gozo que visam suplantar. Pela fantasia, produzse a cena na qual objeto e sujeito se complementam no gozo pulsional. Trata-se de um campo privilegiado de inflamento do Ego, em que o eu pode tudo, a criança pode tudo.

Será lógico apresentar a realidade dessa maneira para criança, exatamente no momento em que o princípio de prazer já domina a cena psíquica? A 
fantasia protoplástica implantada na subjetividade infantil, repleta de desejos e expectativas da alteridade que a cerca, passa a dominar o campo do imaginário, quando outras fantasias originais da criança, que favorecem a maturação psíquica e sexual, deveriam estar em marcha nesse momento. Ao invés de se perguntar "de onde veem os bebês?" ou "o que será feito do meu pênis?", as crianças se interrogam sobre o efeito que certa vestimenta ou adereço terá no Outro do social; o que vestir, o que comprar, como ser melhor? Esse cenário se configura, ao nosso entender, tal como descreveu Winnicott (1982): como um campo privilegiado para a criação de um falso self que orientará a personalidade dessa criança à atender as exigências do mundo, esquecendo-se do percurso necessário em direção à elas mesmas.

Por essas e outras razões, torna-se função da psicanálise denunciar a construção de inúmeros saberes sobre a criança, a partir da modernidade, à medida que ela passa a ter um lugar central na sociedade, sobretudo quando esses saberes terminam por silenciá-la, revelando nossa ignorância em relação à ela devido ao recalque da criança que fomos. Transformá-la em objeto da ciência, em objeto do consumo e da mídia, talvez seja uma forma de tentar responder a essa ignorância de ordem inconsciente, em uma tentativa de objetivá-la através dos saberes racionais (Bosqui \& Martinez, 2009). O infantil permanece no sujeito, independentemente de sua idade, como uma forma de satisfação primária, e condiz aos seus desejos recalcados e suas experiências de desamparo.

\section{Conclusão}

A expressão "provisão ambiental", utilizada tão significativamente por Winnicott (1982), aparece em sua obra associada ao conceito de "ambiente suficientemente bom". Este, quando existente, provê as necessidades vitais e pulsionais do recém-nascido, proporcionandolhe um sentimento de continuidade de ser no tempo e de ser real, uma consciência de si, um self primordial.

A ideia de que o indivíduo se constitui criativamente a partir da provisão ambiental, desenvolvendo processualmente seu potencial inato através de relações interacionais complexas com o mundo, permitiu a Winnicott situar seu pensamento para além dos 
dualismos e reducionismos presentes no paradigma científico que marcou a modernidade. Ele escolheu expressar suas ideias e concepções através de paradoxos, evitando, desse modo, qualquer tipo de dualismo e/ou reducionismo.

O verso do poeta indiano Rabindranath Tagore (1941), Na praia-mar ${ }^{1}$, citado por Winnicott (1975) em seu texto $A$ localização da experiência cultural, nos apresenta uma bela metáfora dessa ambiência inicial que o corpo da mãe oferece ao bebê em seus primórdios: "na praia do mar dos mundos sem fim, mães e crianças brincam". Conhecendo a obra de Winnicott, compreende-se o seu fascínio pelos versos de Tagore.

Então perguntamos: a quem é dado o direito de viver sua infância plenamente? Brincar, ser criança, ser livre, lançar seus barcos de papel ao mar para que cruzem os sete mares, tal como no belíssimo poema de Tagore sobre as estripulias infantis. Podemos perceber que o nosso atual quadro social está repleto de experiências da infância e da adolescência não vividas. Isso porque a sociedade estipula quem pode ou não pode dela fazer parte e quem pode ser o que e quando.

Nesse sentido, Foucault privilegia o aparelho produtor da repressão, evidenciando tecnologias mudas que determinam as encenações institucionais, encenações mudas que reproduzem as estruturas tecnocráticas de poder, quem pode e quem não pode pertencer a quais campos dos diferentes extratos sociais. São frutos das sociedades disciplinares em que a disciplina do corpo se constitui como base do controle e da vigilância, O que se torna útil se for um corpo produtivo e submisso. Devemos notar que tal sujeição pode se dar através da violência do aparelho de repressão do Estado ou das sutilezas da propaganda, das ideologias ou mesmo da fascinação dos pais.

Se analisarmos bem, não parece que vivemos em uma sociedade que acabou de celebrar 25 anos da Lei $\mathrm{n}^{\circ} 8.069 / 90$, que institui as bases do Estatuto da Criança e do Adolescente (Brasil, 1990). Assistimos a tal nível de desinvestimento na infância na atualidade em diversos âmbitos sociais protagonizados por vários atores políticos e familiares, que a criança, em alguns momentos, pode se sentir tão ou mais desamparada do que no período de vigência do terrível código de menores. Um exemplo disso pode ser visto, inclusive, nas classes média e alta, quando a escola de tempo integral assume o lugar de pais e familiares.

Além disso, as crianças das classes pobres, especialmente, são vistas pela sociedade (atendidas, protegidas, medicadas e aprisionadas) tão somente quando apresentam alguma disfuncionalidade (ato infracional, patologia social ou despersonalização da infância). No restante do tempo, muitas delas padecem de uma invisibilidade social torturante, ainda mais quando pensamos no valor que o 
olhar do outro adquire nos processos de formação identitária ou mesmo no direito básico à cidadania que todos deveriam ter.

O problema não é fundamentar direitos, pois esses já existem, a questão é a garantir tais direitos através de práticas sociais e políticas públicas eficazes. O tratamento baseado na segregação, na violência e na exclusão social que permite a equação "louco = perigoso" é o que Basaglia (1985) define como criminalização da doença. A este acrescentaríamos a oposição "menor = criminoso", e "criativo ou diferente $=$ doente". Um crime da paz, um crime realizado através de ações e saberes técnicos, que, por sua vez, o justificam e o ratificam. Assim, a criança é punida através da segregação manicomial e da perda dos direitos e da sua capacidade criativa. Além das instituições, dos saberes e das políticas, é crucial a interpelação que Basaglia dirige aos profissionais, esses "técnicos do saber prático" e executores materiais da violência legalizada e justificada.

Nietzsche (1978) dirá que nada é mais meu do que os meus sonhos. Pensamos que, quando o filósofo fala de sonhos, ele não se refere aos processos oníricos que o sujeito experimenta ao dormir. Esses também são muito nossos, como concluiu Freud; no entanto, as barreias do inconsciente infantil ainda não estão suficientemente estabelecidas e a criança possui acesso bastante amplo aos seus próprios conteúdos recalcados, 
o que torna seus sonhos realizações diretas de seus desejos diurnos. Nietzsche parece se referir aos devaneios que temos quando estamos em vigília, nossas aspirações. O brincar é a materialização dos sonhos acordados da criança, abertura para as infinitas possibilidades de realizar.

Atualmente, estamos negando essa possibilidade às crianças que não têm o direito de serem crianças, e veem seus caminhos atravessados pela judicialização, mercantilização ou medicalização, negando os acessos que irão pavimentar a estrada segura da transição da fantasia infantil para a experiência cultural partilhada da criança para o adulto psicologicamente saudável.

CHILDHOOD AND PSYCHOLOGICAL SUFFERING: MEDICALIZATION, COMMERCLALIZATION, AND LEGALIZATION

\begin{abstract}
Speeches on childhood are being produced in contemporary society? To perform this questioning, in the light of psychoanalysis, it is the main objective of this article, that also encourages the reflection on legalization, medicalization, and commercialization processes of the first stages of life. It is understood that the initial times of development reverberate in the working mode of the subject. So that the ways in which social groups deal with different children influence the future design of each society. This confirms the relevance of thinking on the topic "psychological suffering in childhood and its consequences".
\end{abstract}

Index terms: psychological suffering; childhood; legalization; medicalization; commercialization.

INFANCLA Y SUFRIMIENTO PSICOLÓGICO: LA MEDICALIZACIÓN, MERCANTILIZACIÓN Y JUDICIALIZACIÓN

\title{
RESUMEN
}

¿Cuáles discursos han sido producidos acerca de la infancia en la contemporaneidad? Este cuestionamiento a la luz del psicoanálisis es el objetivo principal de este artículo que también estimula reflexiones con respeto a los procesos de judicialización, medicalización y mercantilización de las primeras fases de la vida. Se entiende que los momentos iniciales del desarrollo resuenan en el modo de operación del sujeto, de hecho que las maneras con las cuales los grupos sociales proceden con sus diferentes niños influenciarán en el futuro proyecto de cada sociedad. Así, se confirma la relevancia de pensar sobre el tema del sufrimiento psíquico en la infancia y sus despliegues.

Palabras-clave: sufrimiento psicológico; infancia; judicialización; me dicalización; mercantilización.

\section{REFERÊNCIAS}

American Psychiatric Association. (2002). Diagnostic and statistical manual for mental disorders. Washington, DC: APA. 
Arbex, D. (2013). Holocausto brasileiro: vida, genocídio e 60 mil mortes no maior hospicio do Brasil. Belo Horizonte, MG: Geração.

Ariès, P. (1981). História social da criança e da familia. Rio de Janeiro, RJ: 2a Editora.

Barletta, J. B. (2011). Avaliação e intervenção psicoterapêutica nos transtornos disruptivos: algumas reflexões. Revista Brasileira de Terapias Cognitivas, 7(2), 25-31.

Basaglia, F. (1985). A instituição negada. Rio de Janeiro, RJ: Graal.

Bezerra Jr., B. C. (2010) A psiquiatria e a gestão tecnológica do bem-estar. In J. Freire Filho (Org.), Ser feliz hoje: reflexóes sobre o imperativo da felicidade. Rio de Janeiro, RJ: FGV.

Birman, J. (2006). Tatuando o desamparo: a juventude na atualidade. In M. Cardoso \& M. Rezende (Orgs.), Adolescentes (pp. 25-43). São Paulo, SP: Escuta.

Bittencourt, M. I. (2012). Meninas, corpo e moda: observaçóes sobre a infância e o consumo. In J. Vilhena, \& J. Novaes (Org.), Corpo pra que te quero: usos, abusos e desusos. Rio de Janeiro, RJ: Appris.

Bosqui, J., \& Martinez, V. V. (2012). Formas de sofrimento psíquico na clínica atual com criança. In Anais do I Encontro Brasileiro de Psicanálise e Sedução Generalizada. Maringá, PR.

Brasil (1990). Estatuto da Criança e do Adolescente. Presidência da República. Recuperado de http://www.planalto.gov. br/ccivil_03/Leis/L8069.htm.

Brum, E. (2014, 17 de março). Como se fabricam crianças loucas. Jornal El Pais.

Calligaris, C. (2004, 2 de maio). O direito à tristeza. Jornal Folha de São Paulo.

Carvalho, I. A., \& Serpa, M. G. (2014). Corpo e embelezamento: a criança participante de concurso de beleza. Psicologia: ciência e profissão, 34(4), 835-849.

Certeau, M. (1994). A invenção do cotidiano. Petrópolis, RJ: Vozes.

Conrad, P. (2007). The medicalization of society: on the transformation of human conditions into treatable disorders. Baltimore, MD: The Johns Hopkins University Press.

Foucault, M. (1998). A história da sexualidade 2: o uso dos prazeres. Rio de Janeiro, RJ: Graal.

Foucault, M. (2000). Vigiar e punir: o nascimento das prisōes. Petrópolis, RJ: Vozes.

Freud, S. (1996a). Três ensaios para uma teoria da sexualidade. In S. Freud, Edição standard brasileira das obras psicológicas completas de Sigmund Freud (J. Salomão, trad., Vol. VII, pp.119-229). Rio de Janeiro, RJ: Imago. (Trabalho original publicado em 1905)

Freud, S. (1996b). Sobre o narcisismo: uma introdução. In S. Freud, Edição standard brasileira das obras psicológicas completas de Sigmund Freud (J. Salomão, trad., Vol. XIV, pp.77-113). Rio de Janeiro, RJ: Imago. (Trabalho original publicado em 1914)

Goffman, E. (1961). Manicômios, prisóes e conventos. São Paulo, SP: Perspectiva.

Lacan, J. (1988). O seminário, livro 7: a ética da psicanálise, 1956-1960. Rio de Janeiro, RJ: Jorge Zahar Editor.

Lacan, J. (1992). O seminário, livro 17: o avesso da psicanálise, 1969-1970. Rio de Janeiro, RJ: Jorge Zahar Editor.

Lacan, J. (1998). Subversão do sujeito e dialética do desejo no inconsciente freudiano. In J. Lacan, Escritos. Rio de Janeiro, RJ: Jorge Zahar Editor.

Lacan, J. (2005). O seminário, livro 10: a angústia, 1962-1963. Rio de Janeiro, RJ: Jorge Zahar.

Lipovetsky, G. (2007). A felicidade paradoxal: ensaio sobre a sociedade do hiperconsumo. São Paulo, SP: Cia das Letras.

Marafon, G. (2014). Judicialização da infância: da menoridade à prevenção do bullying. Revista Entreideias, 3(1), p. 79-93.

Nietzsche, F. (1978). Assim falou Zaratustra. Sáo Paulo, SP: Hemus.

Pereira, M. E. C. (2007). Diagnóstico e alienação, ou "Dr., meu filho é TDAH". In Anais do Fórum de linguagem da UFRJ: clinicas da linguagem III. Rio de Janeiro, RJ.

Rosa, M. D. (2005). Gozo e política na psicanálise: a toxicomania como emblemática 
dos impasses do sujeito contemporâneo. In M. D. Rosa, Trauma e psicanálise. São Paulo, SP: Pulsional.

Serra-Pinheiro, M. A., Schmitz, M., Mattos, P., \& Souza, I. (2004). Transtorno desafiador de oposição: uma revisão de correlatos neurobiológicos e ambientais, comorbidades, tratamento e prognóstico. Revista Brasileira de Psiquiatria, 26(4), 273-276.

Sodré, M. (1994). A máquina de Narciso. São Paulo, SP: Cortez.

Veras, L. (2015). Aqui se jaz, aqui se paga: a mercantilização da morte, do morrer e do luto. Rio de Janeiro, RJ: Appris.

Vilhena, J., Zamora, M. H., \& Rosa, C. M. (2012). Da lei dos homens à lei da selva: sobre adolescentes em conflito com a lei. Revista Trivium, 3(2), 27-40.

Winnicott, D. W. (1963). O ambiente e os processos de maturação: estudos sobre a teoria do desenvolvimento emocional. Porto Alegre, RS: Artes médicas.
Winnicott, D. W. (1975). O brincar e a realidade. Rio de Janeiro, RJ: Imago.

Winnicott, D. W. (1982). Psicose e cuidados maternos. In D. W. Winnicott, Textos selecionados: da pediatria à psicanálise. Rio de Janeiro, RJ: Francisco Alves.

Winnicott, D. W. (1987). Privação e delinquência. São Paulo, SP: Martins Fontes.

carlosmendesrosa@gmail.com

\section{NOTA}

1. Do original em inglês: "On the Seashore". A epígrafe de Winnicott usa uma estrofe modificada do verso original de Tagore (1941): "On the seashore of endless worlds, children meet". Winnicott escreve: "On the seashore of endless worlds children play". A troca do verbo "meet" (encontrar) por "play" (brincar), enfatiza o tema táo amplamente explorado por Winnicott em seu artigo sobre o brincar e a experiência cultural.

carlosmendesrosa@gmail.com Quadra 604 Sul, Alameda 12, 45, Qi. J. Casa 1 77022-032 - Palmas - TO - Brasil.

lanaveras@hotmail.com

Av. São Sebastião, 3950/18 64202-020 - Parnaíba - PI - Brasil.

vilhena@puc-rio.br

Av. Ataulfo de Paiva, 135/613 22440-901 - Rio de Janeiro - RJ - Brasil.

Recebido em junho/2015. Aceito em agosto/2015. 